\title{
Combating the Consequences of COVID-19 Misinformation: Comparative Analysis
}

\author{
Maia Penzer ${ }^{1}$ and Alycia Breig* \\ ${ }^{1}$ Half Hollow Hills East High School, Dix Hills, NY, USA \\ \#Advisor
}

\section{ABSTRACT}

The subject of media literacy among adolescents is particularly relevant due to the rapid dissemination of information online, the lack of media literacy education in secondary curricula on Long Island, New York, and the prevalence of social media in the twenty-first century. This study looks at the effect of COVID-19 misinformation on the believability, level of concern, and mood of high school and middle school students on Long Island, New York in 2021. This study included high school and middle school students from four Long Island school districts. Students were given a survey that included three misinformation sources, a concern level scale, and a mood scale. As a result of this investigation, a comparative analysis of student data was compiled. While middle school students had higher believability rates than high school students, resulting in negative mood changes and high concern levels, high school students also demonstrated high levels of believability of the COVID-19 misinformation, resulting in negative mood changes and high concern levels. Early adolescent media literacy education is critical to avoiding the unpleasant mood changes and increased concern levels caused by the high believability of COVID-19 misinformation. This study demonstrates that, just as we discovered during the pandemic how critical it is to stop virus transmission, it is also critical to stop the spread of misinformation about COVID-19. Both put people in danger. Combating the negative effects of COVID19 misinformation necessitates media literacy education.

\section{Introduction}

Now more than ever, the subject of media literacy ${ }^{1}$ among adolescents, ages 11-18, is of critical importance due to the increased spread of information online, the lack of media literacy education in secondary curricula on Long Island, New York, and the prevalence of social media in the 21 st century. As we live through a global pandemic, with an abundance of COVID-19 misinformation ${ }^{2}$ flooding the media, it is imperative that students know how to navigate news media. The "Research" [that is the subject of this report] was designed to investigate the effect of COVID-19 misinformation on adolescents, in order to educate students on the possible consequences that may result from the high believability of false news sources and low media literacy. The results of this study may provide adolescents with insight into the importance of media literacy, by questioning: How does COVID-19 misinformation affect high school and middle school students' believability ${ }^{3}$, concern level, and mood on Long Island, New York in 2021 ?

\section{Literature Review}

\footnotetext{
${ }^{1}$ The ability to access, analyze, evaluate and create media in a variety of forms

${ }^{2}$ False or inaccurate information that is ultimately intended to deceive an audience

${ }^{3}$ The extent to which information is accepted or regarded as true, real and credible
} 


\section{Misinformation Influx}

Within the 21st century, social media is ever-present. The book, Understanding Media and Culture, written by a professor of journalism at Lehigh University, Jack Lule, discusses the significant role that news media plays in today's society by informing, entertaining, and educating the public at a rapid rate. Nevertheless, information is not always factually accurate, and misinformation can be intentionally published for various reasons, including attracting readers and viewers, profit gain, etc. For instance, media researcher Amy Watson conducted a study concerning false information in the media, finding that 29 percent of survey respondents believe social media sites were largely responsible for the spread of "fake news" (Watson, 2019). Because of this misinformation influx within the media, adolescents with weak media literacy may be at risk for lack of critical thinking skills, which may negatively affect student concern levels and mood due to the high believability of information online. As misinformation escalates, it is essential to raise awareness about low media literacy among adolescents to avoid the negative consequences that may result from misinformation believability.

\section{High School Student Media Literacy}

Current research suggests that many high school students have difficulty distinguishing fact from fiction online. Sam Wineburg, a founder of the Stanford History Education Group (SHEG), whose studies are frequently mentioned in the media literacy field, utilizes discipline-specific methodology to assess adolescent media literacy and believability. In the media literacy field, presenting misinformation as a way to abstractly evaluate student believability is common. In Wineburg's study, Evaluating Information: The Cornerstone of Civic Online Reasoning, misinformation sources ${ }^{4}$, along with follow-up questions ${ }^{5}$, were presented to 170 high school participants in the format of a written assessment. From this assessment, Wineburg concluded that "less than $20 \%$ of students constructed 'mastery' responses, or responses that questioned the source of the post", indicating weak media literacy and high believability rates among high school students. Similarly, a study conducted by Joel Breakstone, Sam Wineburg, and Mark Smith at SHEG, consisting of 3,446 students, demonstrated that despite a teenager's familiarity with social media, many lack basic critical online evaluation skills. These two studies corroborate each other, concluding that an improvement in teenage media literacy education and research is necessary because "students need to be able to distinguish between legitimate and dubious sources" (Wineburg, 2016).

\section{Middle School Student Media Literacy}

Middle school media awareness and believability outcomes are similar to those of high school students. Middle school students have access to the internet at an extremely young age. According to a survey conducted by Amanda Lenhart, a research specialist at the Pew Research Center, most pre-teens receive their first "smart" cell phones during early adolescence (Lenhart, 2020). Considering the early age at which most pre-teens start to use social media, the need for media literacy education in middle school is essential. To support this, a study conducted in 2016 by Sam Wineberg and Sarah McGrew with middle school, high school, and college students revealed that " $80 \%$ of middle schoolers believed a native (false) ad was a real news story," indicating high rates of middle school believability. It is important to raise awareness about media literacy in middle school, to educate adolescents to view information online through a critical lens.

\footnotetext{
${ }^{4}$ Media literacy researchers commonly use misinformation sources in the form of news headlines, false newspaper articles, and images with misleading content

${ }^{5}$ Misinformation follow-up questions contribute to the explanation of student believability
} 


\section{News Believability and COVID-19}

Few researchers have yet assessed the relevance of media literacy during the COVID-19 global pandemic. Tessa Jolls, President, and CEO at the Center for Media Literacy opines that the importance of knowing how to navigate the web through "dark times" is essential. Due to COVID-19 and public hysteria, many people are often in a state of fear due to an overwhelming amount of information online. However, much of the material saturating the media is misinformation. Therefore, media literacy skills are crucial to calm the fears of the public as well as decrease the chance of a negative mood change and/or increase in concern level as a result of viewing misinformation. To combat this issue, Kathy Katella, Senior Clinical Writer at Yale Medicine, suggests that online users should approach COVID-19 information on social media with skepticism, due to the complicated nature of COVID-19 statistics, graphs, and information. People can be swayed to believe the first thing they view - or read - that seems compelling, which can potentially affect concern levels and mood, and therefore can be detrimental to the mental health of individuals.

Gordon Pennycook, Jonathon McPhetres, Yunhao Zhang, and David G. Rand, from the Massachusetts Institute of Technology (MIT), conducted a study regarding this misinformation in the media during the pandemic which supported both Jolls's and Katella's conclusions. As in both SHEG studies, the MIT research employed the method of providing participants with false news headlines. By doing so, the study showed that a simple method to enhance people's decisions about what to share on social media is to encourage them to think about accuracy. These researchers suggest that, amid a pandemic, media literacy is more essential than ever.

\section{A Push for Media Literacy Education}

The drive for education is widely proposed within the media literacy field due to an increased amount of misinformation online. Vanessa Domine, a professor at Montclair State University with a Ph.D. in Media Ecology from New York University, discussed the importance, and lack, of media education. Domine claims that while literacy education has been a component of most schools' curriculum, schools cannot keep up with the numerous significant technological advances made during this decade. This can be detrimental to students, as proved by a study conducted by Margaret Carmody Hagood, a professor of education at the College of Charleston. Hagood states that since media literacy is an important subject due to the spread of COVID-19 related misinformation online, educators and researchers must discover new ways to instruct students in the process of critical thinking when it comes to evaluating information. These two sources confirm the importance of media literacy education in the classroom and recommend increased research on the negative consequences of low media literacy, which this Research aimed to investigate.

\section{Methodology}

\section{Methodology Introduction}

The purpose of the Research was to determine the effect of COVID-19 misinformation on high school and middle school students' believability, concern level, and mood. Throughout the remainder of the paper, high school students are referred to as "HS" and middle school students as "MS". With inspiration from Wineburg's study, Evaluating Information: The Cornerstone of Civic Online Reasoning, a comparative analysis was conducted. A comparative analysis is defined as a technique used to "analyze and compare two or more objects or ideas. Comparative study shows how two subjects are similar or shows how two subjects are different" (Bukhari, 2011). While Wineburg evaluated the believability of college, MS, and HS students, the model research did not perform a comparative analysis. To add a new concept to the media literacy field, the researcher aimed to concisely compare HS and MS student rates by quantitatively analyzing the students' responses to each survey section. 
This Research hypothesizes that Long Island MS students will have higher believability of the COVID-19 misinformation resulting from a lack of middle school media literacy education, which will influence high concern levels and negative mood changes. By comparison, Long Island HS students are hypothesized to have lower believability rates, which will influence lower concern levels and no mood change due to increased awareness of misinformation in the media. The objective of this Research is to spread awareness about the possible consequences of low media literacy and emphasize the importance of media literacy education among adolescents.

\section{Sampling \& Sample Size}

Since most pre-teens have access to social media and the internet, including MS students in this study was critical to demonstrate the importance of media literacy education beginning in early adolescence. To support these claims, Measuring News Media Literacy, a peer-reviewed study by media specialists Stephanie Craft, Adam Maksl, and Seth Ashley, found that media literacy rates among MS students were extremely low; "[f]or example, almost 60 percent of 14-year-olds are in the low news media literacy group" (Craft et al., 2015). Furthermore, recent research conducted by Sam Wineburg in the model study indicates that many HS students struggle to differentiate fact from fiction online. These studies confirm the value of assessing Long Island HS and MS students to raise awareness about low media literacy and a lack of media literacy education on Long Island, New York. By conducting a cross-sectional study, the researcher compared believability rates, as well as mood change and concern level outcomes, in both age groups.

In addition, within the model study, Wineburg piloted his research with a sample size of 464 participants but eventually reduced his sample population to 170 students. This Research utilized a sample size of 183 participants, including 104 HS students and 79 MS students. A random sample of the participant population was surveyed. This means that no specific student was selected to participate in the research process.

Survey Justification

Although Wineburg's research utilized a written assessment format, this Research used a survey format because an online Google Forms survey allowed anonymous participation and the easy attachment of images, along with the believability, mood, and concern evaluation questions that were adequately aligned with the research topic. The need for individual, though confidential, student believability rates, concern level, and mood evaluation within a limited period justified the use of an online survey rather than a physical written assessment. Also, due to COVID-19 restrictions, the researcher was denied permission to hand out written assessments. Since the survey assessed both MS and HS students, two identical surveys were created for each school. The justification for two separate, yet identical surveys included the need for a comparative analysis of student data. With Google Forms, the data was automatically sorted onto two separate Google spreadsheets: one for MS students and one for HS students. By examining the results, the researcher was able to compare MS and HS believability rates along with concern level and student mood.

\section{Survey Procedures}

As this Research is student-based, research procedures for minors need to be considered. Consent forms were embedded into the Google Forms survey, as it was necessary to inform students and their guardians about their legal rights before they agree to participate in a study (see Appendix B to view the informed consent). HS and MS students in English classes among four Long Island school districts took the survey. The significance of researching English classes is that media literacy mainly centers around context, reading knowledge, and different themes, all of which relate to what students learn in a standard English class. HS students and their guardians were permitted to sign the digital consent form. However, due to the younger ages of MS students and the survey's inclusion of deception, the ethical review board required physical distribution of consent forms, to ensure that MS students did not sign the online form without the consent of a guardian. When the analysis was completed, the researcher debriefed the results with the participants to explain the importance of the study. 


\section{Deception to Assess Believability}

A common method utilized in the field includes presenting misinformation to students as a way to abstractly assess student believability and media literacy. Sam Wineburg used this method in the model study by showing a total of $170 \mathrm{HS}$ students false news headlines with pictures of daisies, claiming they were mutations as a result of a nuclear disaster. Additionally, in Fighting COVID-19 Misinformation on Social Media: Experimental Evidence for a Scalable Accuracy-Nudge Intervention as mentioned previously, COVID-19 misinformation was shown to about 1,700 adult participants, which inspired the researcher to do the same with adolescents. These experiments were replicated as part of this Research to validate previous, successful results on a different age group and in a new setting. This will hopefully educate students about the positive outcomes of media literacy. These two recent studies confirm the viability of presenting misinformation as deception.

\section{COVID-19 Misinformation Headlines}

In keeping with this research method, this study included three COVID-19 related news headlines (see Appendix A to view the news headlines) with follow-up questions for participants to complete. These questions, created for this study, were inspired by Wineburg's study, as they indicate the reasons for student believability. The questions included: "Are the claims made in this post accurate?" and "If you answered yes to the previous question, what factor made you do so?" (Figure Four). Two of the news headlines are from the study Fighting COVID-19 Misinformation on Social Media: Experimental Evidence for a Scalable Accuracy-Nudge Intervention, one of which makes false claims about the virus, and one of which is factual. To test factors that influence one's believability, the researcher added a verification checkmark into the factual news source since in the model study, Wineburg had "[s]tudents identify the blue checkmark that distinguishes a verified account from a fake one", which determined whether students would believe a piece of information solely based on user verification. The third headline was a second false news headline from the website dailymail.co.uk. Having two false headlines and one true headline ensured that the believability assessment was representative. Due to previous research success with adult subjects, the researcher did the same with adolescents, since there is no research in the field that does so.

\section{Mood and Concern Level Evaluation}

In addition to the assessment of student believability, mood change and concern level were evaluated, as no research in the field has yet tested these variables among both HS and MS students on Long Island, New York. To test student mood as a result of viewing the COVID-19 misinformation, the survey included one self-produced mood evaluation question (Figure Three). Students who indicated that their mood changed from positive to negative as a result of viewing the COVID-19 information will demonstrate that false information had a negative impact on student mood. This emphasizes the need for media literacy education.

To operationally define the concern level of students after viewing the misinformation, a Likert scale from 1 (not concerned at all) to 4 (very concerned) was utilized, per the aforementioned study Fighting COVID-19 Misinformation on Social Media: Experimental Evidence for a Scalable Accuracy-Nudge Intervention. Although the study used a Likert scale ranging from 0 to 100, the researcher concluded that a Likert scale ranging from 1 to 4 would be adequate for this Research and would keep the task simple and brief for students. For this Research, students who chose a 1 or 2 on the Likert scale were considered not concerned about the COVID-19 misinformation while students who chose a 3 or 4 were considered concerned. 
Please fill in the choice that describes your current mood after viewing the COVID-19 Information:

My mood changed from positive to negative

My mood changed from negative to positive

No mood change

Figure Three:

\section{Methodology Limitations}

The methodology utilized has multiple limitations. For example, it is possible that a student's negative shift in mood or concern level may not have resulted from viewing the misinformation, but rather from an external source. This may be a confounding variable that affects the results. To combat this issue, the survey asked about changes in mood or concern level specifically as a result of viewing the information. Also, students' outside knowledge concerning COVID-19, could influence their responses to the misinformation follow-up questions. As a result, it may appear that students can discern fact from fiction online when, in fact, they already know about the subject or believe the source based on the appearance. Thus, the survey contains variables for students to choose from that may lead to their assessment of news headlines (Question Two), based on Wineburg's research, shown in Figure Four below.

\begin{tabular}{|l|}
\hline If you answered "yes" to the previous question, which factor made you do so? \\
\hline User verification \\
\hline Previous knowledge \\
\hline Research \\
\hline Looks credible \\
\hline I did not answer "yes" \\
\hline Other \\
\hline
\end{tabular}

Figure Four:

\section{Results}

A total of 183 participants from four Long Island school districts were used in this study. HS students made up 104 of the participant population, while MS students made up 79.

\section{Deception: High School Students}

Two false news headlines along with one true news headline (see Appendix A to view the news headlines) were presented to students along with two questions following each news source. Question One asked, "Are the claims made in this post accurate?" and Question Two asked, "If you answered yes to the previous question, what factor made you do so?"

The HS students' answers for Question One of false Headline One are shown in Graph One below. 65\% of HS students stated that they did not know whether the false news headline was accurate, $32 \%$ stated that the headline 
was not accurate, and 3\% stated that it was accurate. Thus, the HS results suggest weak media literacy as less than $\frac{1}{3}$ of students could identify the headline as inaccurate. Although more than half of HS students did not know whether the misinformation was accurate, $3 \%$ of students thought that the source was factual. However, when participants were asked Question Two, 3\% of HS students stated that the headline was accurate because the source "looked credible," suggesting that the appearance of a news source influenced student believability. Additionally, $1.1 \%$ of students stated that they had previous knowledge of the subject, and $93.5 \%$ did not answer yes.

\section{Graph One:}

Question One False Headline One: Are the claims made in this post accurate?

75

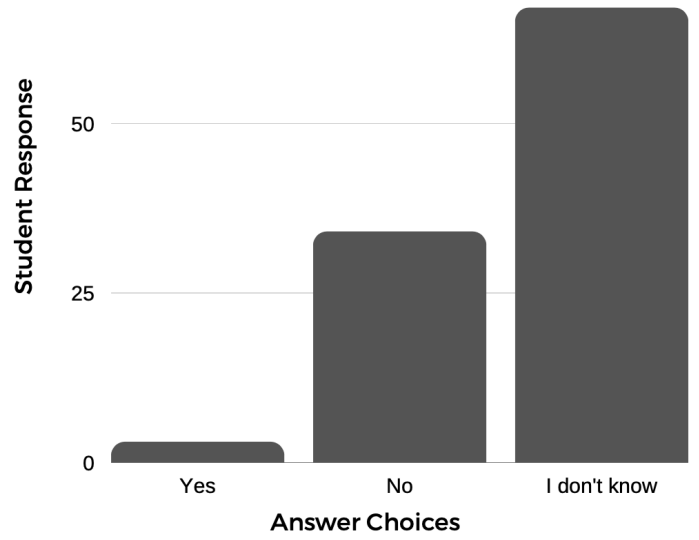

HS student responses to Headline Two, a false news headline from dailymail.co.uk, differ from the responses to false Headline One. The HS student responses for Question One of false news Headline Two are shown in Graph Two below. $51 \%$ of HS students stated that the false news headline was accurate, $20 \%$ stated that they did not know, and $28 \%$ stated that it was not accurate. However, when asked Question Two, 50.5\% of HS students stated that they believed the headline, again, because it "looked credible," $7.4 \%$ of students stated that they had previous knowledge on the subject matter, and $41.1 \%$ of students did not answer yes. Thus, it is shown that almost half of HS participants base content credibility on the appearance of a news source.

Graph Two:

Question One False Headline Two: Are the claims made in this post accurate?

60

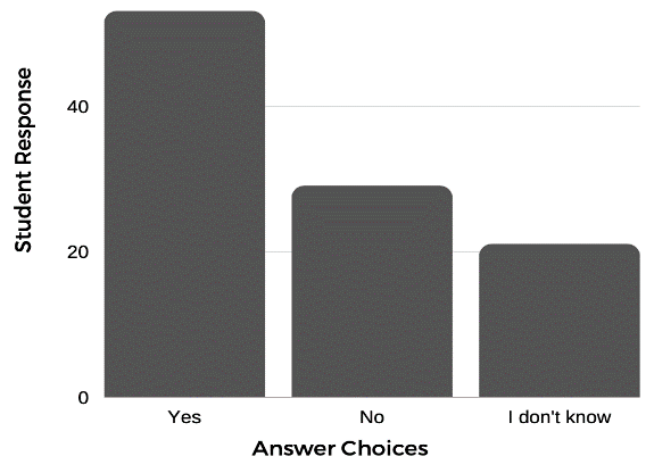


Headline Three is the true headline with a verification check mark added by the researcher to test if students believe a news source based on user verification. The HS student answers for Question One of true Headline Three are shown in Graph Three below. 54\% of HS students stated that the news source was true, 33\% of students did not know, and $12 \%$ of students stated that the source was inaccurate. However, when asked Question Two, $51.1 \%$ of HS students stated that user verification indicated a factual source, which is false because the content can still be inaccurate. In addition, $5.3 \%$ of HS participants stated that they believed the source because it "looked credible", 5.3\% stated that they had previous knowledge on the subject, $1 \%$ of students stated that they did research, and $36.2 \%$ did not answer yes. Therefore, the increase in the believability of the factual source was attributable to graphics such as user verification and appearance, rather than concrete research and media literacy skills.

Graph Three:

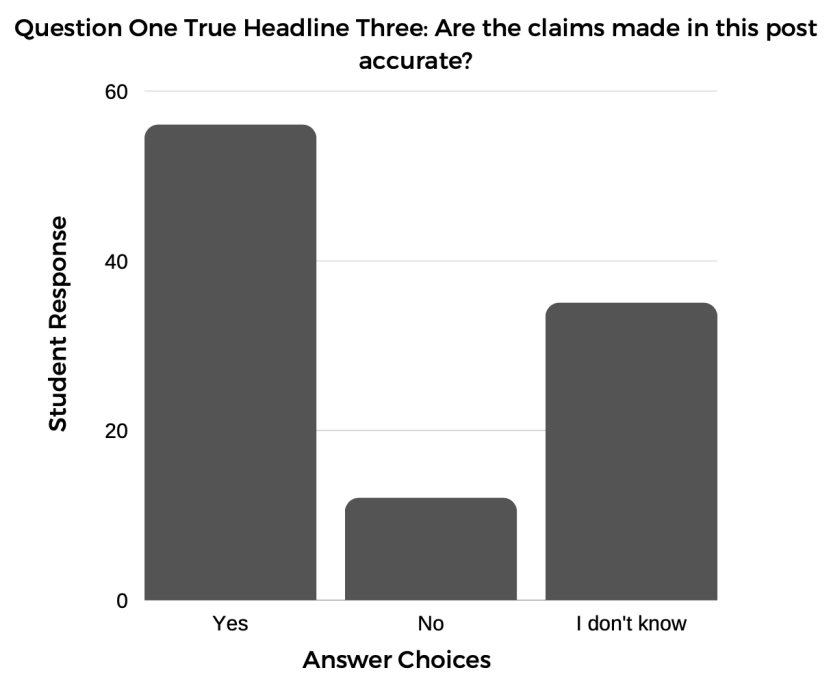

Deception: Middle School Students

The MS student answers for Question One of false Headline One are shown in Graph Four below. 81\% of MS students stated that they did not know whether the false news headline was accurate, $8.9 \%$ of students stated that the headline was not accurate, while $10.1 \%$ stated that it was accurate. Therefore, the MS participants show similar results to HS media literacy within false Headline One, as more than half of the students were not aware of the false information, and $10.1 \%$ of MS students believed the misinformation presented. The low percentage of MS students who thought the source was accurate, similar to the HS findings, suggested that false Headline One is a true source because it "looked credible." 
Graph Four:

Question One False Headline One: Are the claims made in this post accurate?

75

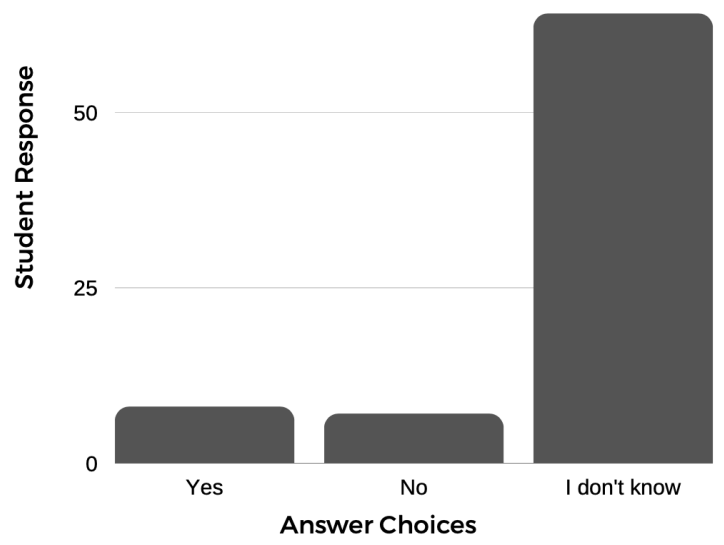

The MS student responses for Question One of false Headline Two, are shown in Graph Five below. 88.6\% of MS students stated that the false news headline was accurate, $3.8 \%$ stated that they did not know, and $7.6 \%$ stated that it was not accurate. However, $86.1 \%$ of MS students stated that they believed the false headline since it "looked credible," $2.5 \%$ of students stated that they had previous knowledge on the subject matter, $1.3 \%$ stated that they did research, and $10.1 \%$ did not answer yes. Again, MS results are similar to those of HS as the looks of a source influence student believability.

Graph Five:

\section{Question One False Headline Two: Are the claims made in this post accurate?}

100

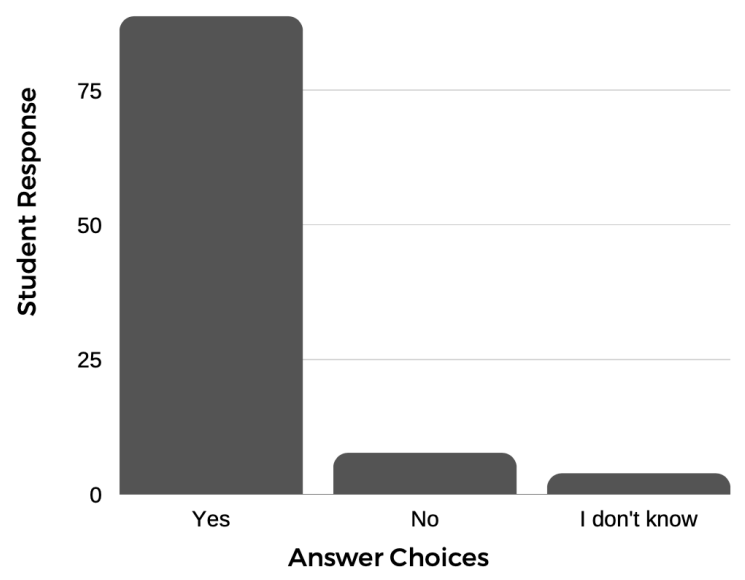

The MS student answers for Question One of true Headline Three are shown in Graph Six below. 94.9\% of MS students stated that the news source was true, $5.1 \%$ of students did not know, and $0 \%$ of students stated that the source was inaccurate. When asked Question Two, however, $86.1 \%$ of MS students stated that user verification indicated a factual source, which significantly exceeds the $51.1 \%$ of HS students who stated that user verification indicated a factual source. In addition, $6.3 \%$ of MS participants stated that they believed the source because it "looked credible", 
$2.5 \%$ stated that they did research, and $5.1 \%$ did not answer yes. Similar to HS performance, MS believability is primarily focused on visuals, such as user verification and presentation, rather than media literacy abilities.

Graph Six:

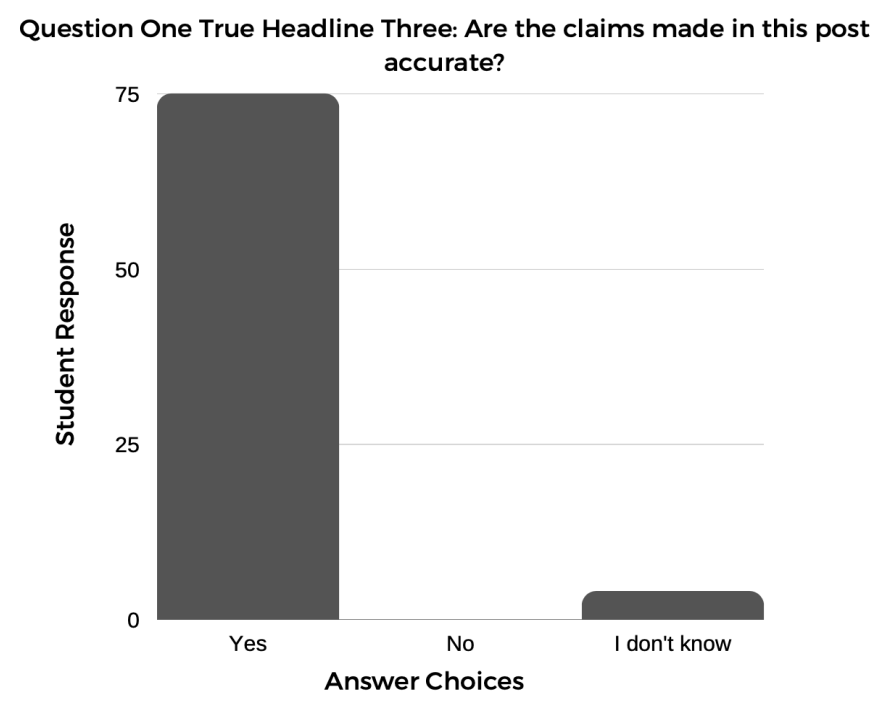

Concern and Mood: High School Students

Concern level and student mood were assessed in this study to identify if misinformation believability may influence negative mood change and increased concern level. First, students were asked, "As a result of viewing these claims, how would you rate your concern level on a scale of 1 (not concerned at all) to 4 (very concerned)?" In total, 74.8\% of the HS students rated themselves as concerned, while $25.2 \%$ did not (Graph Seven). In addition, after viewing the COVID-19 information, 52.4\% of HS participants indicated no mood change, $45.6 \%$ stated that their mood changed from positive to negative, and $1.9 \%$ of HS students stated that their mood changed from negative to positive (Graph Eight).

Graph Seven:

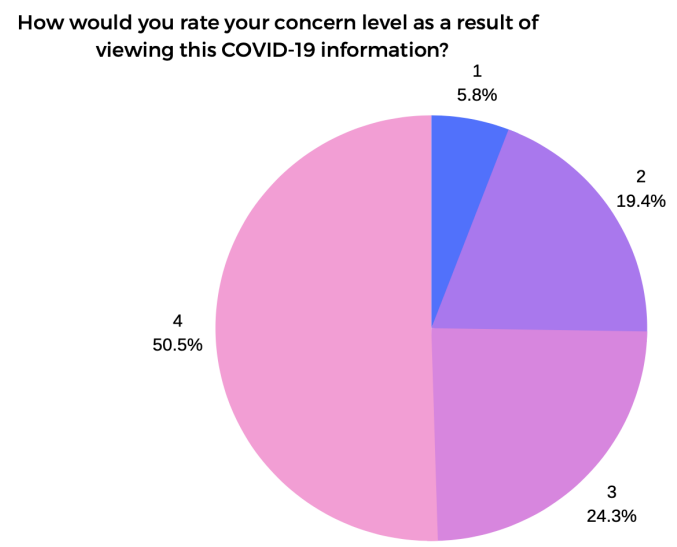




\section{Graph Eight:}
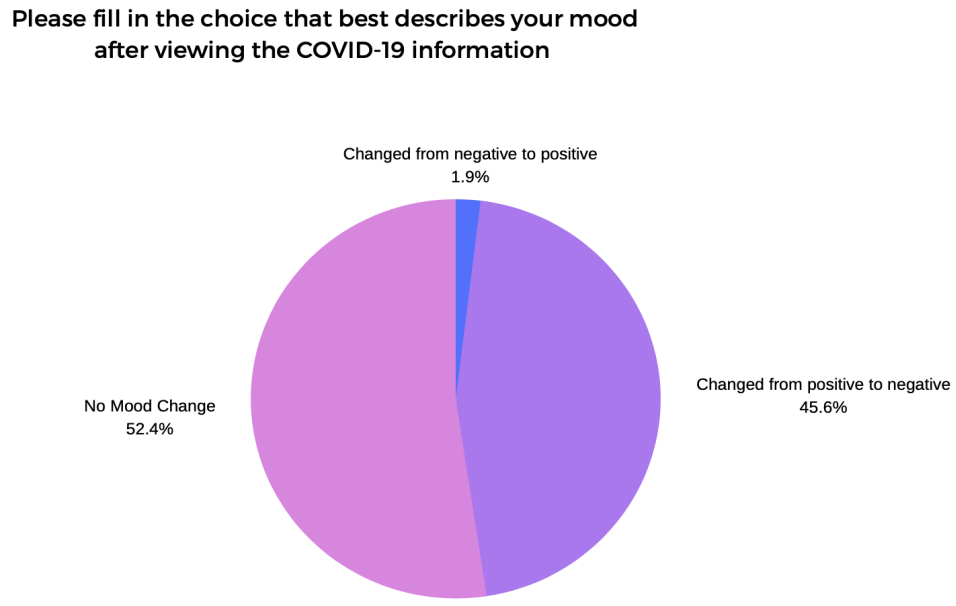

\section{Concern and Mood: Middle School Students}

The results of the MS student concern scale are shown in Graph Nine below. In total, 93.7\% of MS students rated themselves as concerned, while $6.4 \%$ did not. As shown by these results, MS concern level surpasses HS concern level by $18.9 \%$, indicating that misinformation affected MS students more strongly. In addition, after viewing the COVID-19 information (Graph Ten), 17.7\% of MS participants indicated no mood change, $82.3 \%$ stated that their mood changed from positive to negative, and $0 \%$ of students stated that their mood changed from negative to positive. Although this is similar to the HS mood assessment, the MS mood assessment showed a more significant shift, with almost all students reporting that misinformation had a significant negative impact, showing that a lack of media literacy can have negative consequences.

Graph Nine:

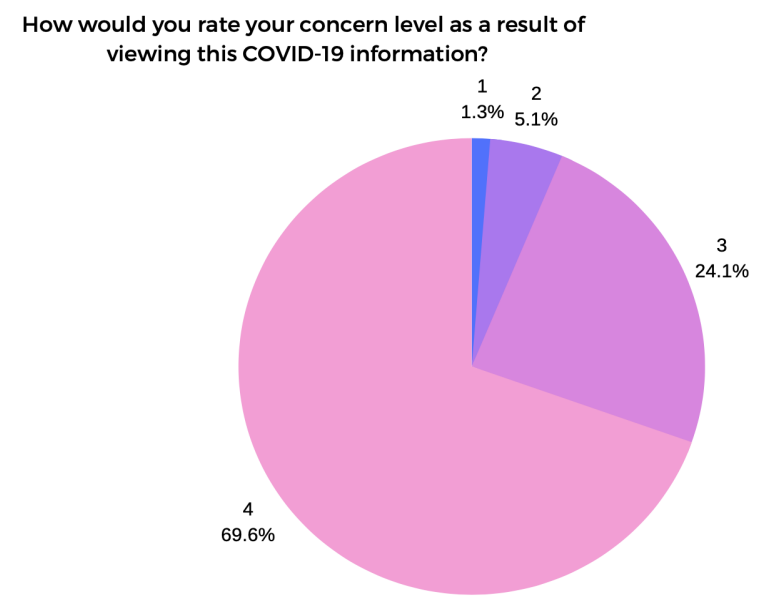


Graph Ten:

Please fill in the choice that best describes your mood after viewing the COVID-19 information

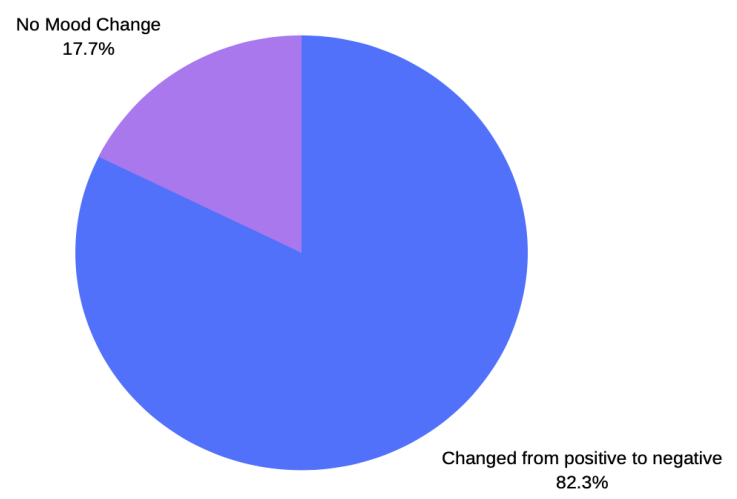

\section{Discussion \& Implications}

Through the Research findings, it can be concluded that both MS and HS students have a high level of believability, which impacts concern level and influences negative mood change as a result of viewing COVID-19 misinformation. The initial hypothesis that MS students will have higher believability, thus influencing high levels of concern and negative mood change, was correct; MS students displayed a higher rate of believability due to the appearance of the headlines. The second part of the researcher's hypothesis, however, was incorrect; HS students also showed high rates of believability based on a source's appearance, which resulted in high levels of concern and negative mood changes. Similar to Sam Wineburg's study, Evaluating Information: The Cornerstone of Civic Online Reasoning, this Research confirmed that student believability is heavily influenced by the appearance of a news source. In Wineburg's research, it was shown that almost all of the students assessed based source credibility on looks, and did not question reliability, as "students across grade levels were captivated by the photograph and relied on it to evaluate the trustworthiness of the post. They ignored key details, such as the source of the photo" (Wineburg, 2016). Likewise, the results of this Research demonstrate that both MS and HS students show high rates of believability due to a source's appearance, however, MS believability rates were higher than HS rates, bolstering the case for media literacy education starting in early adolescence. The presence of a source, along with user verification, played a significant role in student believability, which, in turn, negatively influenced student concern and mood, as seen by the results of the deception portion of the study.

This Research shows that misinformation does play a role in the shift in mood and level of concern, as more than half of MS and HS students expressed high levels of concern and a negative mood shift after viewing the COVID19 misinformation. The negative consequences of high believability among adolescents on Long Island, New York may have been caused by a lack of media literacy skills and education, which can be avoided with an instructional emphasis on discerning misinformation in schooling. 


\section{Possible Solutions}

Through Wineburg's research, it was concluded that his "results suggest the need for further instruction on how to best navigate social media content". As Wineburg's study greatly inspired this Research, the implementation of increased media literacy education, specifically starting in MS on Long Island, New York, is a newly proposed solution that may assist students when viewing sources online and investigating the legitimacy of news media before evaluating the reliability. A drawback of this approach, however, is that some school districts on Long Island, New York may not implement media education as part of the in-class curriculum. Therefore, another strategy for combating this issue is for Long Island school districts to create and distribute media literacy awareness sessions online for all students to access. Adolescents would be able to conveniently access media literacy education from the comfort of their own homes. Thus, when students are faced with COVID-19 news, they can use the media applications offered by their school to assist them when evaluating the credibility of news sources.

\section{Future Research \& Limitations}

Several limitations were revealed after this analysis was completed. These included that as this Research was conducted over a span of seven months, time restraints limited larger sample sizes. Since Wineburg piloted his research with a total of 464 participants before it was reduced to 170, this study should be repeated in future research to match a sample size of around 500 participants to see if the same results are replicated within a larger sample pool. In addition, there were 25 more HS students than MS students in the researcher's sample size. This difference may have skewed the results, which should be considered if the Research is replicated in the future. To see if the findings of this study are consistent, future studies should seek to include the same number of HS and MS participants.

Another limitation of the study included the use of a survey method. Although a survey provided for anonymous participation and widespread dissemination, due to a lack of understanding of the subject, participants may not be aware of their reasons for any given answer. As a result, they could have simply chosen a random response due to a lack of awareness of the topic or boredom. Therefore, in future studies, this Research should be repeated in the form of a written evaluation, similar to that utilized in Sam Wineburg's study, rather than an online survey, to avoid limiting students' responses.

Also, since this Research was conducted on Long Island, New York, the results do not accurately represent the entire population of MS and HS students in New York State or elsewhere. As a result, future studies should replicate this Research across various geographic locations to see whether the findings remain consistent. Finally, future research should look into the effects of media literacy education beginning in middle school on Long Island, New York, along with the addition of online media literacy information sessions, to see whether they mitigated the negative mood shifts and high levels of concern influenced by the high believability of misinformation among adolescents.

\section{Conclusion}

This Research explored the effect of COVID-19 misinformation on HS and MS students' believability, concern level, and mood on Long Island, New York in 2021. Based on these results, the researcher concludes that media literacy education starting in MS on Long Island, New York, is essential to avoid the negative consequences of high believability and lack of critical thinking skills. These skills are essential during a time of vastly increased social media usage and misinformation, especially as we live through a global pandemic. Just as we have learned over the course of the pandemic how important it is to stop the spread of the virus, this Research demonstrates that it is equally important to stop the spread of misinformation regarding COVID-19. Both put people at risk. Media literacy education is the key to combating the negative consequences of COVID-19 misinformation. 


\section{References}

Adolescence (11-18). (n.d.). Retrieved April 26, 2021, from http://www.accordalliance.org/dsdguidelines/htdocs parents/adolescence.html

[Author removed at the request of original publisher]. (2016, March 22). 1.3 The Evolution of Media.

Retrieved November 02, 2020, from https:/open.lib.umn.edu/mediaandculture/chapter/1-3-the-evolutionof-media/

Bergan, D., \& Lee, H. (2018). Media Literacy and Response to Terror News. Journal of Media Literacy Education, 10(3), 43-56. https://doi.org/10.23860/JMLE-2018-10-3-3

Breakstone, J., Wineburg, S., \& Smith, M. (2020, May 20). Civic Online Reasoning. Retrieved November 2, 2020 , from

https://stacks.stanford.edu/file/druid:gf151tb4868/Civic\%20Online\%20Reasoning\%20National20Portrait.pdf

Brenan, M. (n.d.). Four in five Americans concerned misinformation will influence the election. Retrieved November 02, 2020, from https://knightfoundation.org/articles/four-in-five-americans-concernedmisinformation-will-influence-election

Bukhari, S. (2011, November 21). What is comparative study. Retrieved April 25, 2021, from https:// papers.ssrn.com/sol3/papers.cfm?abstract_id=1962328

Bulger, M., \& Davison, P. (n.d.). The promises, challenges, and futures of media literacy. Retrieved April 25, 2021, from https://digitalcommons.uri.edu/jmle/vol10/iss1/1/

Chapter 5 How Can We Help Our Students? (2017). Library Technology Reports, 53(8), 29+. https://link.gale.com/ apps/doc/A521876904/AONE?u=nysl_li_halfhol\&sid=AONE\&xid=abb9ca

Dobo, N. (2020, March 30). A shocking number of young people can't separate fact from fiction online. Retrieved November 02, 2020, from https://hechingerreport.org/shocking-number-young-people-cant-separate-fact-

fiction-online/

Domine, V. (2013). The Coming of Age of Media Literacy. Journal of Media Literacy Education, 3(1). Retrieved from https://digitalcommons.uri.edu/jmle/vol3/iss1/5

Education Group, S. H. (2016, November 16). Evaluating information: The cornerstone of civic online reasoning. Retrieved November 2, 2020, from https://stacks.stanford.edu/file/druid:fv751yt5934/

SHEG\%20Evaluating\%20Information\%20Online.pdf

Gebel, M. (2021, January 15). Misinformation vs. disinformation: What to know about each form of false information, and how to spot them online. Retrieved April 26, 2021, from

https://www.businessinsider.com/misinformation-vs-disinformation

Gordon Pennycook, J. (n.d.). Fighting COVID-19 misinformation on Social Media: Experimental Evidence for a Scalable ACCURACY-NUDGE Intervention - Gordon Pennycook, Jonathon McPhetres, Yunhao ZHANG, Jackson G. Lu, David G. rand, 2020. Retrieved April 25, 2021, from https:// journals.sagepub.com/doi/full/10.1177/0956797620939054

Hagood, M. C. (2013). Media Literacy Education: On the Move. Journal of Media Literacy Education, 3(1). Retrieved from https://digitalcommons.uri.edu/jmle/vol3/iss 1/6

High school students are unprepared to judge the credibility of information on the Internet, according to Stanford researchers. (2019, November 18). Retrieved April 26, 2021, from https://news.stanford.edu/pressreleases/2019/11/18/high-school-studd-spot-fake-news/

Jolls, T. (n.d.). Media Literacy in the Time of COVID-19. Retrieved November 02, 2020, from https:/www.fosi.org/good-digital-parenting/media-literacy-time-covid-19

Katella, K. (2020, April 13). A COVID-19 'infodemic'? How to make sense of what you're reading. Retrieved April 25, 2021, from https:/www.yalemedicine.org/news/covid-19-infodemic 
Kohnen, A., Mertens, G., \& Boehm, S. (n.d.). Can middle schoolers learn to read the web like experts? Possibilities and limits of a strategy-based intervention. Retrieved November 02, 2020, from https://digitalcommons.uri.edu/jmle/vol12/iss2/6/

Lenhart, A., Ling, R., Campbell, S., \& Purcell, K. (2020, August 27). Teens and mobile phones. Retrieved April 25, 2021, from https://www.pewresearch.org/internet/2010/04/20/teens-and-mobile-phones/

Measuring News Media Literacy - ERIC. (n.d.). Retrieved November 2, 2020, from https://files.eric.ed.gov/fulltext/EJ1059962.pdf

Media Literacy in the Risk Society: Toward a Risk Reduction Strategy. (n.d.). Retrieved April 25, 2021, from https://doi.org/10.2307/20054150

Pratt, N., \& Madnick, S. (2008, January 01). Measuring data BELIEVABILITY: A Provenance Approach. Retrieved April 26, 2021, from https://dspace.mit.edu/handle/1721.1/102857

Stanford Study Finds Most Students Vulnerable To Fake News. (2016, November 22). Retrieved November 02, 2020, from https://www.npr.org/2016/11/22/503052574/stanford-study-finds-most-students-vulnerable-tofake-news

Vanessa Chalmers Health Reporter For Mailonline. (2020, November 06). Children's Covid risk is higher because of how cough droplets fall. Retrieved April 25, 2021, from https://www.dailymail.co.uk/news/article8922333/Children-face-greater-risk-catching-coronavirus-cough-droplets-fall.html

Watson, A. (n.d.). Topic: Fake news. Retrieved April 25, 2021, from https://www.statista.com/topics/3251/fakenews/

Wineburg, S., \& Mcgrew, S. (2020, April 21). Why can't students google their way to the truth (opinion). Retrieved April 25, 2021, from https://www.edweek.org/teaching-learning/opinion-why-students-cant-google-theirway-to-the-truth/2016/11

\section{Appendix A}

\section{COVID-19 News Headlines}

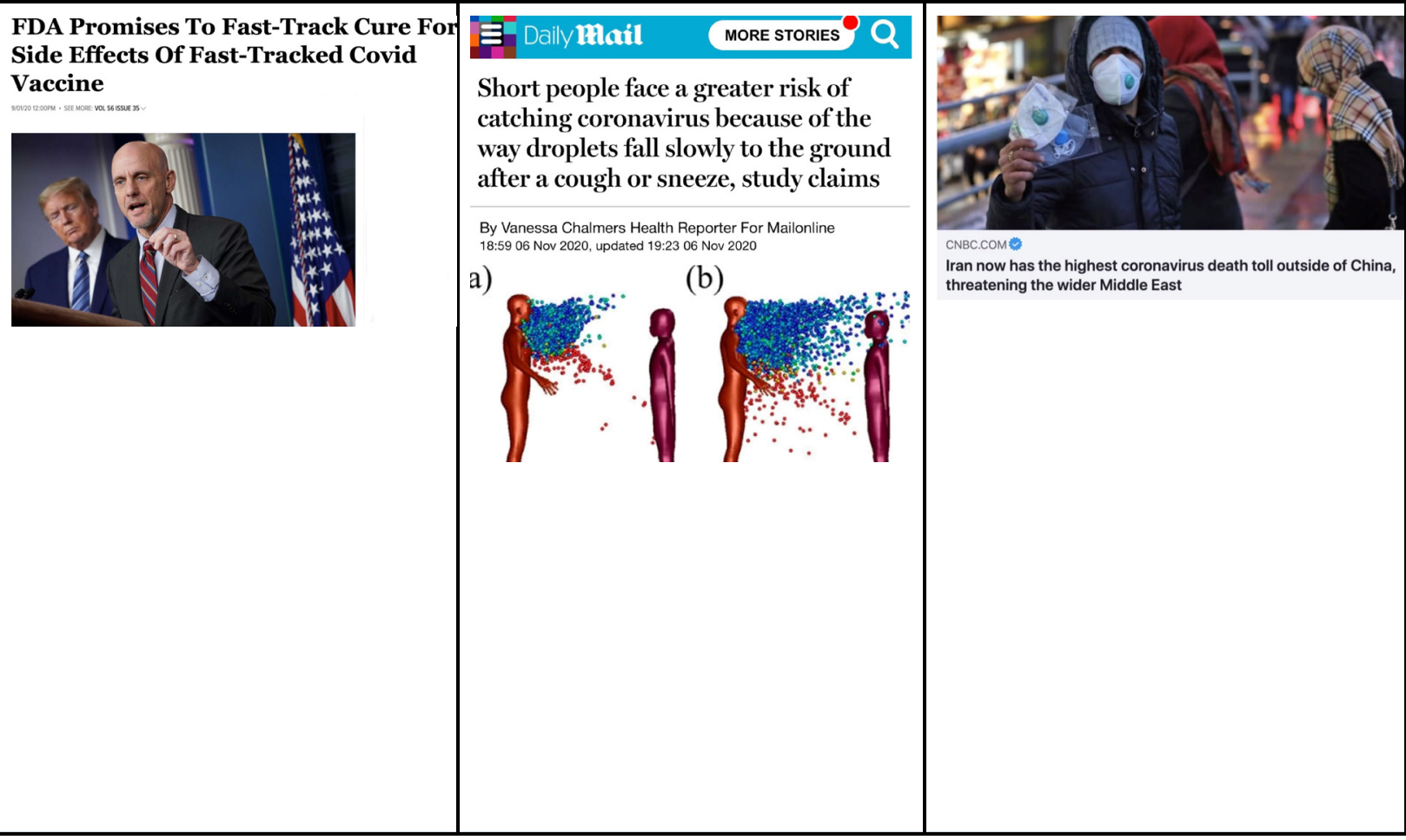




\begin{tabular}{|l|l|l|}
\hline $\begin{array}{l}\text { False Headline 1: } \\
\text { (Pennycook et al., 2020) }\end{array}$ & $\begin{array}{l}\text { False Headline 2: } \\
\text { (Vanessa Chalmers Health } \\
\text { Reporter For Mailonline }, \\
\text { 2020) }\end{array}$ & $\begin{array}{l}\text { True Headline 3: } \\
\text { (Pennycook et al., 2020) }\end{array}$ \\
\end{tabular}

